\title{
Differential running in rats under an alternating (FR 2) schedule in an automated runway
}

P. V. HANFORD, Indiana University, Indianapolis, Ind. 46202, and J. ZIMMERMAN, Indiana University School of Medicine, Indianapolis, Ind. 46207

Performance of rats in an automated runway was reinforced on an alternating (FR 2) schedule. The Ss ran consistently faster during reinforced trials than during nonreinforced trials. This result is in agreement with those previously obtained by others using manually-operated runways, and does not support the possibility of accounting for previous results on the basis of experimenter-introduced cues.

Rats which have been exposed to alternating nonreinforced and reinforced trials in a runway, run faster on trials leading to reinforcement than on trials leading to nonreinforcement (i.e., Capaldi, 1958; Tyler, Wortz \& Bitterman, 1953). Among others, Surridge \& Amsel (1965a, b) have suggested that this alternation may be generated, in part, as a consequence of the use of manual procedures. That is, Ss may be given subtle differential cues on reinforced $(R)$ and nonreinforced $(N)$ trials. Among such cues could be those arising from differential handling of Ss or differential olfactory stimulation provided by baited and nonbaited goal boxes. Harris \& Thomas (1966), however, generated alternation with a runway apparatus and feeding procedure which eliminated the necessity of handling Ss between trials and which eliminated differential olfactory cues, respectively. These investigators joined together three straight runways to form a triangle. A compartment at the vertex of each angle was half goal box and half start box. The E stood in the center of the triangle and operated doors which separated each goal box and start box and each start box and runway. He also operated a manual feeder only after the animal entered the goal box on reinforced trials. Because Harris and Thomas still employed manual operations, however, it could be argued that their results may have been influenced by subtle cues differentially associated with $P$. and $N$ trials.

The purpose of the present study was to examine behavior maintained under an FR 2 schedule of runway performance under conditions in which manual procedures were not utilized. This was accomplished with an automated runway apparatus.

\section{APPARATUS}

The automated runway described previously by Hanford.\& Zimmerman (1967) served as the apparatus. The runway consists of three legs which together with one wall of a Sk inner box form a 2 -ft square. Entrance into and exit from the three-legged runway is controlled by two doors located at opposite ends of the Sk inner box. These doors open in one direction only, permitting $S$ to move through the apparatus in a clockwise direction only. A bar and liquid magazine dispenser are located on the front wall of the Skinner box adjacent to the door through which the $S$ enters the box from the alley. Photo cells are located in the runway 6 in. from each door. Programming equipment is housed in a control room adjacent to the room in which this apparatus is placed.

\section{SUBJECTS}

The four male albino rats used in the previous study (Hanford \& Zimmerman, 1967) served as Ss. In that study, they were exposed daily to a 60-trial session in which each trial terminated in reinforcement. At the start of each of those sessions, $\mathrm{S}$ was placed in the apparatus and not handled again until the end of the session. At the onset of each trial, two house lights mounted in the rear wall of the Sk inner box (immediately adjacent to the door leading from the box to the alley) were illuminated. When $S$ tripped the photocell which was located 6 in from the door leading to the Skinner box, the rear house lights were extinguished and simultaneously two house lights mounted on the front wall of the Skinner box were illuminated. A bar press extinguished the front house lights and activated the magazine producing 4-sec access to $0.20 \mathrm{cc}$ of an equal mixture of chocolate milk and condensed milk. Following the termination of the magazine cycle, the rear lights were illuminated, setting the occasion for the next trial.

\section{PROCEDURE}

Each $\mathrm{S}$ was maintained at $80 \%$ of its free-feeding weight. Each $S$ was first exposed daily to a 120-trial session under an FR 2 schedule. That is, reinforced $(R)$ and nonreinforced $(N)$ trials were alternated in the fixed pattern $N R$ N $R$ until the 60 th $R$ trial was completed. $R$ trials were programmed in the same manner as were the trials previously described above. $\mathrm{N}$ trials were similarly programmed except that a bar press did not activate the magazine, but instead immediately extinguished the front house lights and simultaneously illuminated the rear house lights starting the subsequent $R$ trial.

As Ss were repeatedly exposed to the above conditions on a daily basis, each slowed down so markedly on the $\mathrm{N}$ trials that by the 20 th day, we were unable to run all four within the same 24-h period. As a consequence, we subsequently exposed them to a staggered regimen which permitted us to run two Ss on odd days and the remaining two Ss on even days. Under this new regimen, deprivation was increased to $48 \mathrm{~h}$ and the number of trials per session was increased to 240 . Three Ss performed for 20 consecutive sessions under these conditions while the fourth $S$ performed for 18 consecutive sessions.

Each $S$ was subsequently exposed to 34,120 -trial sessions in which reinforcement was programmed on each trial (continuous reinforcement). During these sessions, the 48-h deprivation regimen remained in effect.

Three performance measures were taken in every trial. These were: (a) starting time, (b) running time, and (c) goal approach time. Starting time was the elapsed time between the onset of the rear lights and the interruption of the first photo cell. Running time was the elapsed time between the interruption of the first photo cell and the interruption of the second photo cell. Goal approach time was the elapsed time between the interruption of the second photo cell and the bar press. These times were automatically recorded for each trial with a three-channel printout counter driven by a pulsing electronic timer.

\section{RESULTS AND DISCUSSION}

For each of the three performance measures, session medians were separately computed for (a) the $R$ trials under the FR 2 schedule, (b) the $\mathrm{N}$ trials under the FR 2 schedule, and subsequently (c) the trials under the continuous reinforcement schedule. Fig. 1 summarizes the results obtained with each $S$ over the final three sessions under each of the two schedules. The top, middle, and bottom rows present the starting times, running times, and goal approach times, respectively. Each bar presents the mean of the final three session medians obtained for the indicated $S$ under the indicated condition. Fig. 1 shows that under the FR 2 schedule, $\mathbf{N}$ times were consistently longer than $\mathbf{R}$ times with 


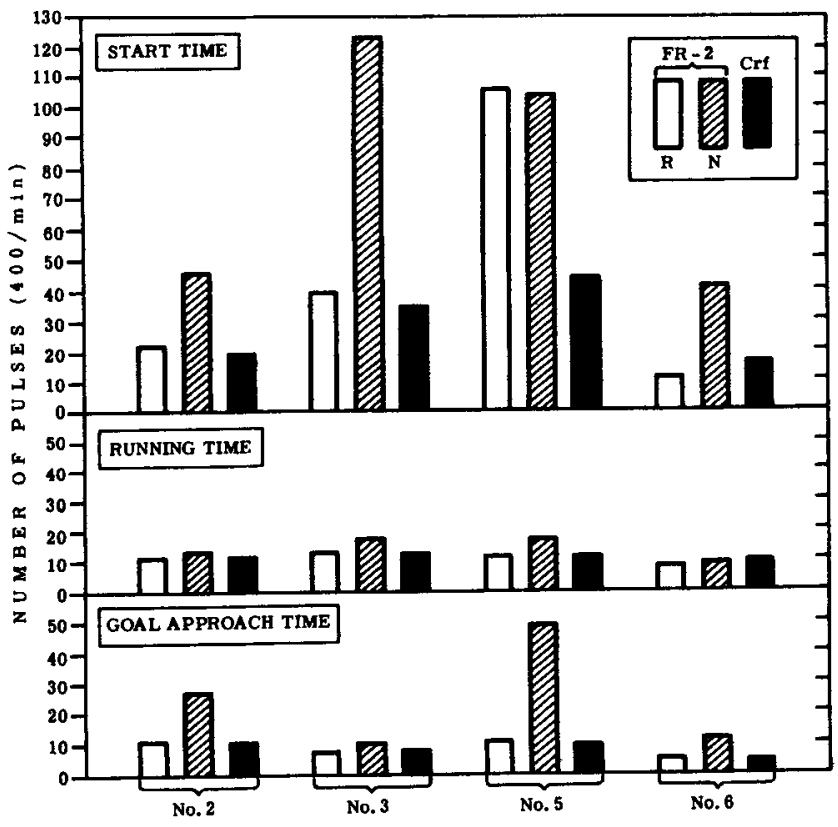

Fig. 1. Mean time for each of the three performance measures under the $R$ (reinforced) trials and $N$ (nonreinforced) trials of the FR 2 schedule and under all trials of the continuous reinforcement ( $\mathrm{Crf})$ schedule.

only one exception (starting time measures for S5). These results replicate the findings of Capaldi (1958) among others. Since the present results were obtained under conditions which could not have permitted $S$ to be influenced by subtle E-provided cues, they lend no support to the alternative hypotheses suggested by Surridge \& Amsel (1965a, b).

Figure 1 also shows that $\mathrm{N}$ times were also consistently longer than trial times obtained under subsequent exposure to the continuous reinforcement schedule, again with only one exception (running time measures for S6). In contrast, no consistent differences were noted between $R$ times generated under the FR-2 and CRF schedules. These results suggest that differences obtained between $R$ and $N$ trials under the FR 2 schedule cannot simply be accounted for on the basis of satiation effects of the just-obtained reinforcement.

Finally, a further analysis of the data (not shown) indicated that alternation behavior generated with the automated runway was extremely reliable across sessions and Ss. Comparisons of the three daily $\mathrm{N}$-trial medians with the corresponding R-trial medians for each of the four Ss under each of the last three sessions of exposure to the FR 2 schedule showed that $\mathrm{N}$-trial times were longer than R-trial times in all but two of the 36 cases.

The consistency of our data in combination with the fact that our results are in agreement with results obtained by workers using conventional runways, point up the advantages of using an automated apparatus. Information about runway performance can be obtained without the possible introduction of $\mathrm{E}$ bias and without the tedium of manually operating a runway. Indeed, while our rats dine in the runway, we dine at the snack bar.

\section{REFERENCES}

CAPALDI, E. J. The effects of different amounts of training on the resistance to extinction of different patterns of partially reinforced responses. Journal of Comparative \& Physiological Psychology, 1958, $51,367-371$.

HANFORD, P. V., ZIMMERMAN, J., \& LECKRONE, W. R. An automated runway and Skinner box apparatus. Psychonomic Science, $1967,8,99-100$.

HARRIS, J. H., \& THOMAS, G. J. Learning single alternation of running speeds in a runway without handling between trials. Psychonomic Science, 1966, 6, 329-330.

SURRIDGE, C. T., \& AMSEL, A. Performance under a single alternation schedule of reinforcement at 24-hour intertrial intervals. Psychonomic Science, 1965a, 3, 131-132.

SURRIDGE, C. T., \& AMSEL, A. A "patterning" effect that seems unrelated to aftereffects from reward and nonreward. Psychonomic Science, 1965b, 3, 373-374.

TYLER, D. W., WORTZ, E. C., \& BITTERMAN, M. E. The effect of random and alternating partial reinforcement on resistance to extinction in the rat. American Journal of Psychology, 1953, 66, 57-65.
(Gallistel, 1966, 1967) and even after 10-15 sec (Johnson, 1968; Johnson, Lobdell, \& Levy, in preparation). One is forced to ask why hypothesized aversive aftereffects show no sign of decay after $60 \mathrm{sec}$. In addition, the longer the intertrial interval, the more the animals seem to prefer ICS. While the present results cannot be considered conclusive, they offer no comfort to the aversive ICS hypothesis.

\section{REFERENCES}

BALL, G. Electrical self-stimulation of the brain and sensory inhibition. Psychonomic Science, 1967, 8, 489-490.

BALL, G., \& ADAMS, D. Intracranial stimulation as an avoidance or escape response. Psychonomic Science, 1965, 3, 39-40.

DEUTSCH, J. A., \& HOWARTH, C. I. Some tests of a theory of intracranial self-stimulation. Psychological Review, 1963, 70, 446-460.

GALLISTEL, C. Motivating effects in self-stimulation. Journal of Comparative \& Physiological Psychology, 1966, 62, 95-101.

GALLISTEL, C. Intracranial stimulation and natural reward: Differential effects of trial spacing. Psychonomic Science, 1967, 9, 167-168.
JOHNSON, R. Effects of intracranial reinforcement intensity and distributional variables on brightness reversal learning in rats. Journal of Comparative \& Physiological Psychology, 1968, 66, 422-426.

JOHNSON, R., LOBDELL, P., \& LEVY, R. Intracranial self-stimulation and the rapid decay of frustrative non-reward. Manuscript in preparation.

OLDS, J., \& MILNER, P. Positive reinforcement produced by electrical stimulation of septal and other regions of the rat brain. Journal of Comparative \& Physiological Psychology, 1954, 47, 419427.

OLDS, M. E., OLDS, J. Approach-avoidance analysis of the rat diencephalon. Journal of Comparative Neurology, 1963, 120, 259-295.

ROBERTS, W. Rapid escape learning without avoidance learning motivated by hypothalamic stimulation in cats. Journal of Comparative \& Physiological Psychology, 1958, 51, 391-399.

NOTE

1. This research was supported by Grant MH16147-01 from the National Institute of Mental Health, United States Public Health Service. 